\title{
理论与实践融合 : 高师院校与中小学对接培养创新人才
}

Integration of Theory and Practice: Connecting Normal Colleges with Primary and

Secondary Schools to Cultivate Innovative Talents

曾琴 明华

Qin Zeng Hua Ming

内江师范学院图书馆

中国·四川 内江 641000

Library of Neijiang Normal University,

Neijiang, Sichuan, 641000, China

基金项目:四川省普教科研资助金课题

研究项目 “理论与实践融合: 高师教育

与基础教育对接研究”部分研究成果
【摘要】教师向创新人才迈进是比较流行的一种潮流, 在基础教育中,一些中小学教师 由于学历层次较低, 缺乏过硬的专业理论知识以及研究技能, 导致这一目标的实现非常困 难。想要解决这一问题, 多数中小学校选择加强和高师院校之间的合作对接。为此, 论文将 对理论与实践进行有效融合,对高师院校和中小学对接培养创新人才进行分析。

【Abstract】It is a popular trend for teachers to move towards innovative talents. In basic education, some primary and secondary school teachers lack excellent professional theoretical knowledge and research skills because of their low educational level, which makes it very difficult to achieve this goal. To solve this problem, most primary and secondary schools choose to strengthen the cooperation and docking between normal universities. For this reason, the paper will integrate theory and practice effectively, and analyze the cultivation of innovative talents in the docking of normal universities and primary and secondary schools.

【关键词】理论; 实践; 高师院校; 中小学;创新人才

【Keywords】theory; practice; normal colleges; primary and secondary schools; innovative talents 【DOI】10.36012/sde.v1 i2.216

\section{1 引言}

随着新课程改革的逐渐深入，教师的角色已经开始从传 统经验型转变到教育研究者。被引入的一个观念就是“教师转 向研究者,成为创新人才”, 这是国际上非常认可的教育改革 活动。然而在中国中小学校中,部分一线教师长时间在教学领 域中从事工作, 丧失了教育方面的理论知识以及专业技能, 创 新能力十分低下, 要改变这种现状, 与高师院校对接是一种重 要的举措 ${ }^{[1]}$ 。

\section{2 高师院校与中小学对接培养创新人才} 的理论基础与必要性

高师院校与中小学合作对接培养创新人才是当代教育发 展的必然要求,有着广泛的实践背景和浓厚的理论基础,适合
创新人才培养的特点，遵循了教育发展应从基础教育抓起的 内在规律,体现了理论与实践的融合思想。

3 高师院校与中小学对接培养创新人才 存在的问题

\section{1 教师缺失成为创新人才身份的影响因素}

中小学校的教师和高师院校的教师在合作对接过程 中, 丧失了成为创新人才研究者的身份是因为社会大环境 所带来的影响, 受到中小学教师和高师院校研究者特殊性 的影响。

3.1 .1 中小学校教师的特殊性

中小学校教师具有一定的特殊性, 主要体现在他们虽然 拥有比较丰富的教学经验, 教学水平比较高, 但缺乏教学理论 方面的知识,很多教师并没有形成扎实的专业水平。在教学中 
所面对的对象都比较小,学生会提出很多问题,这就要求教师 要有足够的而心去对待教育对象, 而且必须利用比较长的时 间加强和学生之间的沟通, 这样一来, 教师研究时间不充足, 无法形成创新思路,成为创新人才。此外, 在中小学教育中, 女 性教师偏多, 她们工作和生活相对繁忙, 总是缺乏时间和精力 在创新研究事业上。

\subsection{2 高师院校教师的特殊性}

高师院校教师特殊性主要体现在理论学识比较高, 并且 能够长时间做科研, 并不经常在教学的实践工作中出现, 和 中小学校的教师缺乏紧密的联系, 不了解中小学教师身份的 特殊性, 因而在合作对接过程中, 总是一味地包揽研究, 缺乏 对中小学教师创新思想的指导, 而是下达命令让中小学教师 执行, 使对接双方关系紧张, 严重影响了创新人才的培养 ${ }^{[2]}$ 。

\section{2 创新人才培养环境不良}

对于高师院校来说, 未能充分提供创新人才培养的环境, 主要表现在部分教师并未深刻认识到教育的重要性, 在教学 上没有形成一套创新的教学理论, 思想守旧、闭塞, 让很多学 生在毕业之后, 不清楚如何进行创新; 对于中小学校来说, 受 传统教育观念的影响, 一些中小学教师不能很好地认识到创 新人才培养的问题, 并没有营造一个良好的人才成长环境。他 们长期被应试教育下的升学率需求所限制, 没有关注到学生 创新思维培养的重要性, 无法正确认识创新人才的特点与培 养的现实价值。如中小学生的好奇心比较强, 具有很好的灵 感,经常会出现一些奇思妙想,这时,一些教师会让学生立马 端正自身的学习方向, 不能打乱课堂的秩序, 学生的创新个性 被压制。这样的人才培养环境也给高师院校与中小学对接带 来了困扰。

\section{3 缺乏对接的深度}

在实践教学中, 很多高师院校与中小学之间都是缺乏对 接深度的, 对接只是在低层次上的对接, 主要表现在高师院校 的研究人员不能深入到中小学进行实地考察, 多数是在网上 开展一些浅显的交流, 再或是通过电话、邮件和中小学教师取 得联系。当前, 虽然已有高校教师深入到了基层进行相关工 作, 一些高校也选拔了部分教师深入到中小学校举办教育讲 座, 希望可以提升中小学教师的理论水平, 然而由于在基层工 作开展中的时间比较短, 不能及时地引导中小学教师的思想。

\section{4 高师院校与中小学对接培养创新人才}

\section{的措施}

\section{1 转变教师的观念}

中小学教师必须对自身的想法和观念进行很好地转
变, 改变大多数教师认为自己只是中小学的一名普通教 师, 在能力和经验上都非常有限, 认为教育创新人才培养 工作的开展是专业教育人员的事情, 自己肯定不行的消极 思想。就这一问题来说, 教师必须树立自信心, 充分发挥自 身的优势, 深人到创新人才培养的研究工作中, 开拓思维, 赋予前瞻性的构想, 并尝试进行独立申请课题任务, 承担 起研究课题的重任, 使对接具有真实性; 高师院校的教育 研究人员, 必须增强对中小学教师的信任度, 但中小学教 师的地位是非常被动的, 得到的信息并不准确, 不能很好 地开展创新人才的研究工作, 那么, 高师院校研究者就需 要转变观念, 敢于走出大学科研的象牙塔, 深入中小学实 践基地, 尝试和中小学校之间加强联系, 促进其参与度的 提高, 共同进行该研究。

\section{2 加强建设创新型的教师团队, 优化创新人才 培养环境}

高师院校与中小学校都要对创新型的师资队伍进行建 设,制定科学合理的创新人才培养方案, 提升教师自身的各种 素质,使其由原本的知识型发展为现代化的信息型教师,由经 师变为人师。加大激励机制的应用, 让教师以创新为基准点, 开展创新型的教学, 把教师独当一面的课堂变成师生共同拥 有的课堂, 让学生在课堂上充分施展自己的个性, 拓展思维, 满足他们的求知欲, 将学科知识和社会实践进行充分的集合, 形成创新型的教师团队, 形成良好的创新氛围, 优化创新人才 培养环境,促进创新人才的培养。

\section{3 在师资与课程方面进行深度的对接}

高师院校和中小学校对接对于创新人才的培养, 首先就 要对良好的对接关系进行构建, 确保双方是平等民主的, 在 师资与课程内容上实现深度的对接, 构建完整的共同体, 加 大对于创新性人才培养的力度。高师院校教师还要提升自身 的创新能力, 更好地将大学生兴趣与中小学教育结合起来, 选择最适合现阶段大学生学习的教材, 同时保证课程建设的 有效性。

随着新课改的逐渐深入, 高师院校和中小学校之间的对 接已经成为一种趋势, 也是培养社会有用人才的重要途径。对 于相关人员来说, 需要加强对接研究现状分析, 并结合实际问 题制定针对性地措施, 通过理论与实践的融合, 推动中国教育 事业的发展。

\section{参考文献}

[1]张大均.教育心理学[M].北京: 人民教育出版社,2004.

[2]宁虹.教师成为研究者的现象学意识 [J].教育研究,2003(11): 87. 